\title{
The effect of transdermal scopolamine plus intravenous dexamethasone for the prevention of postoperative nausea and vomiting in patients with epidural PCA after major orthopedic surgery
}

\author{
Hyun Kyu Lee, Jae Ho Lee, Sung Sik Chon, Eun Kyoung Ahn, Jin Ho Kim, and Yeon-hee Jang
}

Department of Anesthesia and Pain Medicine, National Health Insurance Corporation Ilsan Hospital, Goyang, Korea

Background: Postoperative nausea and vomiting (PONV) is common complication of Patient-Controlled Analgesia (PCA) after surgery. The authors sought to determine whether a transdermal scopolamine (TDS) patch in combination with IV dexamethasone is more effective than IV dexamethasone alone or IV dexamethasone plus IV ramosetron for reducing PONV in patients receiving epidural PCA after major orthopedic surgery. Methods: 120 patients that received epidural PCA with hydromorphone and ropivacaine after major orthopedic surgery under spinal anesthesia were allocated to 3 groups: Group D $(n=40)$ received IV dexamethasone 8 mg, Group DR $(n=$ 40) received IV dexamethasone $8 \mathrm{mg}$ plus IV ramosetron 0.3 mg, Group DS $(n=40)$ received IV dexamethasone 8 mg plus a TDS patch (Group DS, $n=40$ ). Nausea and vomiting incidences, VAS for nausea, the use of additional antiemetics, and adverse effects (a dry mouth, blurred vision, drowsiness) during the first 24 hours postoperatively were subjected to analysis. Results: The DS Group had a significantly higher rate of complete remission of PONV than the D and DR groups (82.5\% vs 47.5\%, and 50.0\%, respectively), and had lower rates of nausea (17.5\% vs $55.0 \%$, and $50.0 \%$ ), and vomiting (10.0\% vs 50.0\%, and $25.0 \%)$, and required less antiemetics (5.0\% vs 35.0\%, 22.5\%) than group D and Group DR during the first 24 hours after surgery. Furthermore, no inter-group differences were observed with respect to adverse effects in the three groups. Conclusions: The prophylactic use of a TDS patch plus dexamethasone was found to be a more effective means of preventing PONV in patients that received epidural PCA after major orthopedic surgery than dexamethasone alone or dexamethasone plus ramosetron without adversely affecting side effects. (Korean J Anesthesiol 2010; 58: 50 55)

\section{Key Words: Dexamethasone, Epidural PCA, Major orthopedic surgery, PONV, Ramosetron, Transdermal scopolamine.}

Received: September 11, 2009. Revised: 1st, October 5, 2009; 2nd, October 29, 2009. Accepted: November 23, 2009.

Corresponding author: Jae Ho Lee, M.D., National Health Insurance Corporation Ilsan Hospital, Baekseok-dong, Ilsan-gu, Goyang 411-719, Korea. Tel: 82-31-900-0299, Fax: 82-31-900-0138, E-mail: lijhmd@nhimc.or.kr

(c) This is an open-access article distributed under the terms of the Creative Commons Attribution Non-Commercial License (http:// creativecommons.org/licenses/by-nc/3.0/), which permits unrestricted non-commercial use, distribution, and reproduction in any medium, provided the original work is properly cited. 


\section{Introduction}

Patient-Controlled Analgesia (PCA) via the epidural route provides an excellent means of decreasing pain after orthopedic, gynecologic, or abdominal surgery [1]. However, some adverse effects have been reported, especially postoperative nausea and vomiting (PONV). The physical and psychological complications of PONV include; aspiration of vomitus, esophageal trauma (Mallory-Weiss syndrome), dehydration, alkalemia, and emotional depression. Patients are encouraged to begin physical therapy on the day after surgery, but persistent PONV may interfere with physical therapy activities, and this prolongs hospitalization and increases medical costs. A number of therapies are available for the management of PONV, but no therapy is entirely efficient $[2,3]$.

Transdermal scopolamine (TDS) patches are highly effective for managing motion sickness, and were approved in 1997 by the Food and Drug Administration for the prevention of nausea and vomiting after anesthesia. Scopolamine is an anticholinergic agent that acts on the central nervous system by blocking cholinergic transmission from vestibular nuclei to higher CNS centers and from the reticular formation to the vomiting center [4]. Patches contain $1.5 \mathrm{mg}$ of scopolamine and deliver the agent at $5 \mu \mathrm{g} / \mathrm{hr}$ for 72 hours. It has been reported that TDS patches decrease the nausea and vomiting induced by intrathecal or epidural morphine after cesarean delivery $[5,6]$ and other types of surgery $[7,8]$. Furthermore, the prophylactic use of a TDS patch plus ondansetron has been described for the prevention of PONV, and has been found to be superior to ondansetron alone $[9,10]$. However, the combined use of a TDS patch and dexamethasone (a popularly used antiemetic) has not been properly explored, and thus, we compared the effects of a TDS patch plus IV dexamethasone with those of other antiemetics, namely, IV dexamethasone alone and IV dexamethasone plus IV ramosetron, on the prevention of PONV in patients that received epidural PCA after major orthopedic surgery.

\section{Materials and Methods}

Patients that underwent elective, primary, or revisionary total knee or hip replacement surgery or anterior cruciate ligament reconstruction under spinal anesthesia and postoperative epidural PCA were eligible for participation in this study. The study protocol and informed consent forms used were in accordance with the ethical standards issued by our institutional Human Investigation Committee. All patients were of ASA I-III and aged 20-75, and all provided consent on the day before surgery. Patients with the following conditions were excluded; a history of drug-abuse, infection at the lumbar spine, coagulation disorder, uncontrolled diabetes, glaucoma, pregnancy, breast-feeding, a history of dementia, and current steroid use. Patients were allocated to 3 treatment groups using a random numbers table: Group D $(n=40)$ received dexamethasone $8 \mathrm{mg}$ intravenously (Dae Won, Korea); Group DR $(n=40)$ received dexamethasone 8 $\mathrm{mg}$ and ramosetron $0.3 \mathrm{mg}$ intravenously (Nasea ${ }^{\circledR}$, Astellas, Seoul); and Group DS $(n=40)$ received dexamethasone $8 \mathrm{mg}$ and TDS (Kimite, Myung Moon, Korea).

Members of the three groups were similar in terms of age, weight, height, and duration of surgery (Table 1). All patients completed a VAS score for nausea and did not complain of a significant opioid or drug-related adverse effect during the first 24 hours after surgery.

On the day of surgery, patients in the DS group attached a scopolamine patch behind one ear (on the preanesthetic area) at $30 \mathrm{~min}$ before anesthesia. All patients received spinalepidural combined anesthesia (Portex ${ }^{\circledR}$, Smiths Medical, UK) plus $0.5 \%$ hyperbaric bupivacaine (Bupivacaine heavy, Hana Pharm, Korea) 10-12 mg. A 20 gauge epidural catheter was inserted to the L3/4 or L4/5 lumbar spinal level. Combined spinal-epidural anesthesia was sufficient for surgery, and all patients received dexamethasone $8 \mathrm{mg}$ intravenously after confirming level of spinal anesthesia. In addition, members of the DR group were administered ramosetron $0.3 \mathrm{mg}$ intravenously at the end of surgery. Hypotension

Table 1. Demographic Data

\begin{tabular}{lccc}
\hline & Group D $(\mathrm{n}=40)$ & Group DR $(\mathrm{n}=40)$ & Group DS $(\mathrm{n}=40)$ \\
\hline Age $($ year) & $65.3 \pm 9.3$ & $63.9 \pm 10.2$ & $64.8 \pm 11.0$ \\
Sex $(\mathrm{m} / \mathrm{f})$ & $4 / 36$ & $6 / 34$ & $5 / 35$ \\
Weight $(\mathrm{kg})$ & $63.1 \pm 6.6$ & $62.6 \pm 12.6$ & $65.4 \pm 8.4$ \\
Height $(\mathrm{cm})$ & $153.3 \pm 33$ & $153.7 \pm 8.9$ & $153.4 \pm 8.0$ \\
Duration of Surgery $(\mathrm{min})$ & $113.1 \pm 42.2$ & $116.4 \pm 47.3$ & $110.4 \pm 38.1$ \\
Total knee arthroplasty $(\mathrm{n})$ & 31 & 33 & 32 \\
Total hip arthroplasty $(\mathrm{n})$ & 5 & 4 & 4 \\
Ant.cruciate ligament reconstruction $(\mathrm{n})$ & 4 & 3 & 4 \\
\hline
\end{tabular}

Values are numbers or means \pm SDs, $n$ : number of patients. No significant inter-group differences were observed. Group D: the dexamethasone group, Group DR: the dexamethasone plus ramosetron group, and Group DS: the scopolamine plus dexamethasone group. 
during surgery (defined as a systolic blood pressure of $<100$ $\mathrm{mmHg}$ or $>20 \%$ below the prespinal baseline) was treated with boluses of ephedrine $8 \mathrm{mg}$ at the discretion of the attending anesthesiologist. Epidural PCA was started using a PCA pump (Accufuser ${ }^{\circledR}$, Woo Young medical, Korea) at the end of surgery. The pump contained a $150 \mathrm{ml}$ visible bag with hydromorphone 4 g $/ \mathrm{ml}$ (Dilid, Hana Pharm, Korea) and ropivacaine $1 \mathrm{mg} / \mathrm{ml}$ (Naropin ${ }^{\circledR}$, AstraZeneca, Australia). Pump delivery rates were set at $5 \mathrm{ml} / \mathrm{hr}$ and bolus doses at 0.5 $\mathrm{ml}$ with a lockout time of 15 min for 24 hours. Ondansetron 4 mg was administered intravenously as a rescue therapy in the postanesthesia care unit and ward for nausea and vomiting.

Measurements were taken at 0-6, 6-12, and 12-24 h postoperatively. Anesthesiologists (unaware of patient group allocations) recorded the severity of nausea, the presence of vomiting, and the receipt of rescue antiemetics. Severity of nausea was rated using a VAS scale $(0=$ no symptoms and $100=$ worst imaginable symptoms) during each time period. The presence of vomiting and side effects (dry mouth, blurred vision, drowsiness), and the use of rescue antiemetics were also recorded. A pilot study on the incidence of vomiting during the first 24 hours after surgery was performed using 10 patients of each group and $40 \%$ of group D, $20 \%$ of group DR, and $10 \%$ of Group DS were affected. The PASS $2008^{\circledR}$ program (Utah, USA) was used to determine sample sizes, and this analysis showed 34 patients per group were required to achieve $80 \%$ power to detect a linear trend at a significance level 0.05. Statistical analyses were performed using SPSS 14.0 for Windows (Chicago, IL). The One-way ANOVA test with Bonferroni correction was used to analyze parametric data. Categorical data were analyzed using the $\chi^{2}$ test or Fisher's exact test. Statistical significance was accepted for $P$ values of $<0.05$.

\section{Results}

All 120 patients completed a VAS form for nausea, PONV, rescue antiemetics, and adverse effects at each study period. Complete response rates (no nausea, no vomiting) over 24 hours were $47.5 \%, 50.0 \%$, and $82.5 \%$ in groups D, DR, and DS, respectively. The proportions of patients that experienced nausea or vomiting over 24 hours were 55.0 and $50.0 \%, 17.5 \%$

Table 2. Postoperative Nausea, Vomiting, Rescue Antiemetics, and Complete Response Rates and VAS Nausea Scores

\begin{tabular}{|c|c|c|c|c|c|}
\hline & \multicolumn{2}{|c|}{ Group D } & \multicolumn{2}{|c|}{ Group DR } & \multirow{2}{*}{$\begin{array}{c}\text { Group DS } \\
(n=40)\end{array}$} \\
\hline & $(n=40)$ & $P$ & $(n=40)$ & $P$ & \\
\hline \multicolumn{6}{|l|}{ 0-6 $\mathrm{h}$ after anesthesia } \\
\hline Complete response & $31(78 \%)$ & & $24(60 \%)$ & & $36(90 \%)$ \\
\hline Nausea & $9(23 \%)$ & & $15(38 \%)^{\dagger}$ & 0.008 & $4(10 \%)$ \\
\hline Vomiting & $5(13 \%)$ & & $8(20 \%)^{+}$ & 0.029 & $1(3 \%)$ \\
\hline Rescue antiemetics & $4(10 \%)$ & & $6(15 \%)^{+}$ & 0.026 & $0(0 \%)$ \\
\hline VAS for nausea & $11.5 \pm 22.2$ & & $17.5 \pm 27.5^{+}$ & 0.009 & $3.0 \pm 10.1$ \\
\hline \multicolumn{6}{|l|}{ 6-12 h after anesthesia } \\
\hline Complete response & $25(63 \%)^{*}$ & 0.019 & $25(63 \%)^{\dagger}$ & 0.019 & $35(88 \%)$ \\
\hline Nausea & $15(38 \%)^{*}$ & 0.008 & $15(38 \%)^{\dagger}$ & 0.008 & $4(10 \%)$ \\
\hline Vomiting & $11(28 \%)^{*}$ & 0.037 & $3(8 \%)$ & & $3(8 \%)$ \\
\hline Rescue antiemetics & $8(20 \%)$ & & $4(10 \%)$ & & $2(5 \%)$ \\
\hline VAS for nausea & $29.5 \pm 29.2^{*}$ & 0.004 & $12.1 \pm 21.6$ & & $3.5 \pm 11.1$ \\
\hline \multicolumn{6}{|l|}{ 12-24 h after anesthesia } \\
\hline Complete response & $27(68 \%)^{*}$ & 0.003 & $28(70 \%)^{\dagger}$ & 0.006 & $38(95 \%)$ \\
\hline Nausea & $13(33 \%)^{*}$ & 0.003 & $11(28 \%)^{\dagger}$ & 0.013 & $2(5 \%)$ \\
\hline Vomiting & $8(20 \%)^{*}$ & 0.029 & $5(13 \%)$ & & $1(3 \%)$ \\
\hline Rescue antiemetics & $6(15 \%)^{*}$ & 0.026 & $4(10 \%)$ & & $0(0 \%)$ \\
\hline VAS for nausea & $15.4 \pm 24.3^{*}$ & 0.004 & $10.9 \pm 22.4$ & & $1 \pm 4.4$ \\
\hline \multicolumn{6}{|c|}{ 0-24 h after surgery (overall) } \\
\hline Complete response & $19(48 \%)^{*}$ & 0.001 & $20(50 \%)^{\dagger}$ & 0.002 & $33(83 \%)$ \\
\hline Nausea & $22(55 \%)^{*}$ & 0.001 & $20(50 \%)^{+}$ & 0.004 & $7(18 \%)$ \\
\hline Vomiting & $20(50 \%)^{*}$ & 0.000 & $10(25 \%)$ & 0.139 & $4(10 \%)$ \\
\hline Rescue antiemetics & $14(35 \%)^{*}$ & 0.001 & $9(23 \%)^{\dagger}$ & 0.048 & $2(5 \%)$ \\
\hline
\end{tabular}

Values are numbers and percentages (\%). Group D: the dexamethasone group, Group DR: the dexamethasone plus ramosetron group, and Group DS: the scopolamine plus dexamethasone group. ${ }^{*} \mathrm{P}<0.05$ in group D vs group DS, ${ }^{\dagger} \mathrm{P}<0.05$ in group DR vs group DS. 
Table 3. Adverse Effects in the Three Treatment Groups

\begin{tabular}{lccc}
\hline & $\begin{array}{c}\text { Group D } \\
(\mathrm{n}=40)\end{array}$ & $\begin{array}{c}\text { Group DR } \\
(\mathrm{n}=40)\end{array}$ & $\begin{array}{c}\text { Group DS } \\
(\mathrm{n}=40)\end{array}$ \\
\hline $\begin{array}{c}\text { 0-6 h after anesthesia } \\
\text { Visual disturbance }\end{array}$ & $0(0.0 \%)$ & $0(0.0 \%)$ & $0(0.0 \%)$ \\
Dry mouth & $23(57.5 \%)$ & $22(55.0 \%)$ & $22(55.0 \%)$ \\
Drowsiness & $6(15.0 \%)$ & $7(17.5 \%)$ & $3(7.5 \%)$ \\
6-12 h after anesthesia & & & \\
Visual disturbance & $0(0.0 \%)$ & $0(0.0 \%)$ & $0(0.0 \%)$ \\
Dry mouth & $26(65.0 \%)$ & $16(40.0 \%)$ & $23(57.5 \%)$ \\
Drowsiness & $10(25.0 \%)$ & $3(7.5 \%)$ & $10(25.0 \%)$ \\
12-24 h after anesthesia & & & \\
Visual disturbance & $0(0.0 \%)$ & $0(0.0 \%)$ & $0(0.0 \%)$ \\
Dry mouth & $18(45.0 \%)$ & $14(35.0 \%)$ & $21(52.5 \%)$ \\
Drowsiness & $8(20.0 \%)$ & $6(15.0 \%)$ & $5(12.5 \%)$ \\
\hline
\end{tabular}

Values are numbers and percentages (\%). No significant differences were observed between the three groups. Group D: the dexamethasone group, Group DR: the dexame-thasone plus ramosetron group, and Group DS: the scopolamine plus dexamethasone group.

and $50.0 \%$, and $25.0 \%$ and $10.0 \%$, respectively, and the overall proportions of patients who required rescue antiemetics during the same postoperative period were $35.0 \%, 22.5 \%$, and $5.0 \%$ in groups D, DR, DS, respectively (Table 2).

Patients in group DS had significant lower nausea VAS scores at 6-12 and 12-24 hours than patients in group $D(P=0.004)$ and at $0-6$ hours than patients in group $D R(P=0.009)$. The incidence of vomiting was significantly lower at 6-12 and $12-24$ hours in group $D S$ than in group $D(P=0.037,0.029)$, and at $0-6$ hours than in group $D R(P=0.029)$. The proportion of patients who required rescue antiemetics was significantly lower in group DS than in group $D$ at $12-24$ hours $(P=0.026)$, and than in group DR at 0-6 hours $(P=0.026)$ (Table 2). None of the 120 patients complained of blurred vision, and no significant inter-group difference was observed for dry mouth or drowsiness (Table 3). Other adverse effects, such as, agitation, hallucination, and amnesia, were not observed.

\section{Discussion}

Recently, dexamethasone and 5-HT3 receptor antagonists have been used to prevent chemotherapy-induced nausea/vomiting and PONV. This is because corticosteroids may reduce 5 -HT3 levels in neural tissues by depleting its precursor tryptophan [11], and because their antiinflammatory effects may prevent serotonin release in the gut [12]. Furthermore, a combination of dexamethasone and 5-HT3 receptor antagonist has been reported to be effective and safe for preventing PONV $[13,14]$. However, in the present study, the overall rate of PONV in groups D and DR were
55\% and 50\%, respectively. Szarvas et al. [15] reported that in patients that have undergone major orthopedic surgery with intrathecal morphine for postoperative pain and prophylactic IV dexamethasone or IV dexamethasone plus ondansetron, the incidences of PONV during the 0-24 hour immediate postoperative period were $67 \%$ and $40 \%$, respectively, which concurs with our results. Furthermore, they concluded that dexamethasone monotherapy lacks efficacy. In addition, they suggested that dexamethasone better controls delayed PONV due to its relatively long biological half-life (36-72 hours). Thus, the 24-hour observation period used in the present study may not have been sufficient to identify the beneficial effects of dexamethasone. Ramosetron has a more potent, longer acting effect against PONV than granisetron [16]. Therefore, we presume that over the longer term, the prophylactic use of dexamethasone plus ramosetron may have a better effect on PONV comparing this study.

Scopolamine is a nonpolar, tertiary amino compound, and a muscarinic acetylcholine antagonist. Its pharmacodynamic characteristics include good absorption in the Gl tract and excellent blood-brain barrier penetration. Furthermore, it has peripheral antimuscarinic properties and central sedative, antiemetic, and amnesic effects. When given orally or parenterally, scopolamine has a relative short half-life and many induce considerable dose-dependent adverse effects (such as, vertigo, a dry mouth, drowsiness, a visual disturbance, hallucinations, agitation). Because scopolamine has a narrow therapeutic range, a transdermal form has been developed to minimize the relatively high incidence of side effects associated with orally or parenterally scopolamine. The commercially available TDS patch (4 layers, thickness $0.2 \mathrm{~mm}$, size $2.5 \mathrm{~cm}^{2}$ ) contains a drug reservoir of $1.5 \mathrm{mg}$ and delivers a priming dose of $140 \mu \mathrm{g}$ to achieve a steady state plasma concentration of $56-245 \mathrm{pg} / \mathrm{ml}$. The patch releases $0.5 \mathrm{mg}$ of scopolamine over 3 days (a release rate $5 \mu \mathrm{g}$ ) [4].

Although scopolamine is effective at preventing PONV, concerns have been raised regarding its use because of its undesirable side effects and its relatively slow onset of action. In a systemic review of the efficacy and safety of TDS for the prevention of PONV, Kranke et al. [17] suggested a 17\% reduction in PONV at the expense of a $29 \%$ increase in side effects (visual disturbances and a dry mouth were found to be the most common). Furthermore, they found that the timing of TDS application, that is, the night before surgery, before induction, or during surgery, had no significant bearing on results. However, unlike earlier TDS studies [5-8], recent studies have found no different between prophylactic TDS and other antiemetic regimens with respect to the incidences of side effects. Gan et al. [9] compared an ondansetron group and an ondansetron plus TDS group, and found that the ondansetron plus TDS group showed less PONV and cumulative adverse effects over 48 hours. Sah et al. [10] also 
concluded that TDS better prevented PONV than a placebo after ambulatory cosmetic surgery with minimal adverse effects. White et al. [18] examined the use of TDS after major laparoscopic surgery, and found no difference between a dexamethasone plus TDS group and a dexamethasone plus ondansetron group with respect to PONV and side effects (except late dry mouth). They concluded that TDS is a costeffective alternative to ondansetron. In the present study, the prevalences of the expected side effects of scopolamine (a dry mouth, blurred vision, and drowsiness) in the DS group were not significantly greater than the D and DR groups. No visual disturbance was complained of by any of the 120 study subjects. Furthermore, drowsiness was tolerable, and no patient required specific therapy or TDS discontinuation due to an adverse effect. The present study was confined to patients than underwent orthopedic surgery under spinal anesthesia with epidural PCA, and therefore, they were not administered a cholinesterase inhibitor to reverse the muscle paralysis that might inhibit the action of scopolamine. Some studies have reported that TDS is highly effective at preventing PONV in patients on PCA [19,20], and thus, further studies on the prophylactic use of TDS for PONV are required for other types of surgery.

The present study has some limitations that should be considered. First, we did not include a control group (patients without prophylaxis), because we considered this unethical. Second, our PCA strategies were designed for the first 24 hours after surgery, and thus, further studies for are required to investigate the effects of the prolonged application and its adverse effects. Third, patients were not asked to submit a satisfaction score at the end of the study period. Fourth, all patients had an indwelling urinary catheter, and thus, we could not evaluate the effect of TDS on urinary retention.

Summarizing, the prophylactic use of a transdermal scopolamine patch plus IV dexamethasone was found to be more effective at preventing PONV than dexamethasone alone or dexamethasone plus ramosetron in patients that had undergone major orthopedic surgery on epidural PCA, and was found to have minimal side effects.

\section{Acknowledgements}

This article was supported by Ilsan Hospital research foundation.

\section{References}

1. White PF. Use of patient-controlled analgesia for management of acute pain. JAMA 1988; 259: 243-7.

2. Watcha MF, White PF. Postoperative nausea and vomiting. Its etiology, treatment, and prevention. Anesthesiology 1992; 77: 162-84.
3. Kaufmann MA, Rosow C, Schnieper P, Schneider $M$. Prophylactic antiemetic therapy with patient-controlled analgesia: a double-blind, placebo-controlled comparison of droperidol, metoclopramide, and tropisetron. Anesth Analg 1994; 78: 988-94.

4. Renner UD, Oretel R, Kirch W. Pharmacokinetics and pharmacodynamics in clinical use of scopolamine. Ther Drug Monit 2005; 27: 655-65.

5. Harnett MJ, O'Rourke N, Walsh M, Carabuena JM, Segal S. Transdermal scopolamine for prevention of intrathecal morphine-induced nausea and vomiting after cesarean delivery. Anesth Analg 2007; 105: 764-9.

6. Kotelko DM, Rottman RL, Wright WC. Transdermal scopolamine decreases nausea and vomiting following cesarean section in patients receiving epidural morphine. Anesthesiology 1989; 71: 675-8.

7. Bailey PL, Streisand JB, Pace NL, Bubbers SJ, East KA, Mulder S, et al. Transdermal scopolamine reduces nausea and vomiting after outpatient laparoscopy. Anesthesiology 1990; 72: 977-80.

8. Honkavaara P, Saarnivaara L, Klemola UM. Effect of transdermal hyoscine on nausea and vomiting after surgical correction of prominent ears under general anaesthesia. Br J Anaesth 1995; 74: 647-50.

9. Gan TJ, Sinha AC, Kovac AL, Jones RK, Cohen SA, Battikha $J P$, et al. A randomized, double-blind, multicenter trial comparing transdermal scopolamine plus ondansetron to ondansetron alone for the prevention of postoperative nausea and vomiting in the outpatient setting. Anesth Analg 2009; 108: 1498-504.

10. Sah N, Ramesh V, Kaul B, Dalby P, Shestak K, Vallejo MC. Transdermal scopolamine patch in addition to ondansetron for postoperative nausea and vomiting prophylaxis in patients undergoing ambulatory cosmetic surgery. J Clin Anesth 2009; 21: 249-52.

11. Young S. Mechanism of decline in rat brain 5-hydroxytryptamine after induction of liver trytophan pyrrolase by hydroxycortisone:foles of tryptophane catabolism and kynurenine synthesis. Br J Pharmacol 1981; 74: 695.

12. Fredrikson M, Hursti T, Fürst CJ, Steineck G, Börjeson S, Wikblom $M$, et al. Nausea in cancer chemotherapy is inversely related to urinary cortisol excretion $\mathrm{Br} J$ Cancer 1992; 65: 779-80.

13. Fujii Y, Saitoh Y, Tanaka H, Toyooka H. Granisetron/ dexamethasone combination for reducing nausea and vomiting during and after spinal anesthesia for cesarean section. Anesth Analg 1999; 88: 1346-50.

14. Lopez-Olaondo L, Carrascosa F, Pueyo FJ, Monedero P, Busto N, Saez A. Combination of ondansetron and dexamethasone in the prophylaxis of postoperative nausea and vomiting. Br J Anaesth 1996; 76: 835-40.

15. Szarvas S, Chellapuri RS, Harmon DC, Owens J, Murphy 
D, Shorten GD. A comparison of dexamethasone, ondansetron, and dexamethasone plus ondansetron as prophylactic antiemetic and antipruritic therapy in patients receiving intrathecal morphine for major orthopedic surgery. Anesth Analg 2003; 97: 259-63.

16. Fujii Y, Saitoh Y, Tanaka H, Toyooka H. Comparison of ramosetron and granisetron for preventing postoperative nausea and vomiting after gynecological surgery. Anesth Analg 1999; 89: 476-9.

17. Kranke P, Morin AM, Roewer N, Wulf H, Eberhart LH. The efficacy and safety of transdermal scopolamine for the prevention of postoperative nausea and vomiting: a quantitative systemic review. Anesth Analg 2002; 95: 133-
43.

18. White PF, Tang J, Song D, Coleman JE, Wender RH, Ogunnaike B, et al. Transdermal scopolamine: An alternative to ondansetron and droperidol for the prevention of postoperative and postdischarge emetic symptom. Anesth Analg 2007; 104: 92-6.

19. Semple P, Madej TH, Wheatley RG, Jackson IJ, Stevens J. Transdermal hyosine with patient-controlled analgesia. Anaesthesia 1992; 47: 399-401.

20. Harris SN, Sevarino FB, Ginatra RS, Preble L, O'Conner TZ, Silverman DG. Nausea prophylaxis using transdermal scopolamine in the setting of patient-controlled analgesia. Obstet Gynecol 1991; 78: 673-7. 